\title{
NOTA SOBRE "A METAMORFOSE DO MUNDO"
}

Luiz Hebeche*

SÍNTESE - Com a noção de Metamorfose do Mundo pretendemos elaborar uma ontologia do presente desde o conceito wittgensteiniano de "revelação do aspecto". Ontologia, porém, não é uma ciência, mas a prudência gramatical que lida com as incertezas da condiçāo humana expressas na linguagem. Ao contrário da tradição filosófica que parte da contemplação que se distancia do mundo, partimos do assombro instaurado no cerne da linguagem mesma recorrendo à noção de algo como algo, mas destacando na transitoriedade deste "como" a abertura de sentido, ou seja, a possibilidade de tematizar-se o mundo.

PALAVRAS-CHAVE - Aspecto. Linguagem. Ontologia.
ABSTRACT - By means of the conception of Metamorphosis of the World, we ame at elaborating an ontology of the present from the wittgensteinian concept of aspect-dawning. Ontology, though, is not a science; rather, is the grammatical prudence which deals with the uncertainties of human condition expressed in language. Unlike the philosophical tradition, the starts from akind of contemplation that distances itself from the world, we starts from the puzzlement that lies at the hart of language, resorting to the notion of something as something, but pointing out the changling character of this "as" the openess of the sense, i.e., the possibility of thematizing the world.

KEY WORDS - Aspect. Language. Ontology.

Em nossa época só é concebível uma noção de ontologia que resguarde a crítica imanente do sentido. Uma ontologia da contingência. Essa possibilidade baseia-se na compreensão de que a linguagem não diz algo de algo, pois não há confinamento na gramática e de que, portanto, o significado das palavras é seu uso na linguagem. O uso dá vida ao significado. Quando uma palavra não é mais usada, torna-se sem sentido e desaparece a tradição que a originou. Se entendermos as palavras como instrumentos - Zeug - então temos de reconhecer que só no uso um instrumento se define como tal. E isso quer dizer que não se pode retirar a linguagem de sua operacionalidade como se guardam os talheres na gaveta, ou os copos no armário depois da refeição. O que está presente na linguagem não pode ser subtraído de circulação após haver cumprido alguma tarefa, pois as palavras não são informações de algo que esteja além ou aquém delas. Com a expressão goethiana "no principio era a ação", quer-se dizer que, se a

* Professor de Filosofia da Universidade Federal de Santa Catarina - UFSC e doutorando em Filosofia no Curso de Pós-Graduação da PUCRS. 
linguagem não fosse atividade, haveria hipostasiação metafísica: a ocultação. Porém, se tudo funcionasse "normalmente" e de modo imediato, por que tematizaríamos sobre o significado das palavras? $\mathrm{Na}$ imediaticidade seguir-se-iam regras cegamente. $\mathrm{E}$ essas regras constituiriam o mundo. $\mathrm{O}$ mundo, porém, não é um super conceito, pois pode-se falar de mundo das borboletas, mundo dos colecionadores de quadros ou de selos, e assim por diante. Nossa atenção recai sobre o mundo da consciência ou mundo interior porque, nesse âmbito da linguagem, está o conceito de pensamento que, junto ao de aspecto, é crucial para a noção de metamorfose do mundo. O conceito de interior, que delineia um aglomerado-deatividades-afins, é como uma ontologia regional. O mundo interior como contraposto ao exterior confunde-se com a diversidade dos conceitos psicológicos que se encontram na linguagem ordinária. Retornar até eles pressupõe a tarefa de despsicologização da psicologia. O processo cognitivo - e a bipolaridade da proposição - pressupõem uma linguagem que não é resultante de nenhum processo cognitivo, isto é, ela é um âmbito que já não se pode mais ultrapassar sem se recorrer a um retrocesso que se confunde com a ocultação. A linguagem ordinária, porém, não é definida meramente por uma auto-referência em que tudo seria "normal". Se o significado das palavras se dá no fluxo da vida e se se rejeita o modelo objeto-designação, isso quer dizer que os conceitos psicológicos presentes na linguagem ordinária são expressão da condição humana. A vagueza da linguagem indica que originariamente o mundo interior não é um lugar tranqüilo e que essa é a fonte de todo o debate filosófico. Contra a noção de que a auto-referência da linguagem ordinária se caracteriza pela serenidade da terra natal - Heimat partimos, ao contrário, da posição de que há falhas no mundo, de que a linguagem possui uma indeterminação radical; portanto, de uma concepção mundana e dispersiva da linguagem, pois a auto-referencialidade da linguagem ordinária se encontra fissurada no aspecto, e essa fissura não é o vazio ou o sem-sentido, mas a abertura para o outro. E é isso que permite o recurso aos meios de apresentação para melhor visualizar o que já está presente e constituir novas perspectivas de mundo. A noção de metamorfose do mundo torna-se possível à medida que este surge no aspecto, pois, neste, o mundo desvia-se de si mesmo. A metamorfose do mundo é a ação que o repõe sempre sob novas perspectivas. Na oscilação dos aspectos a linguagem ameaça andar no vazio, e é isso que dá um caráter dramático à nossa relação com a metafísica: o que torna possível a emergência do sentido tende também a ocultá-lo. Surge aí o fascínio pelo oculto. E tudo ocorre assim porque a linguagem não opera de modo unilateral. O limite desse operar é o espanto que surge no aspecto, uma vez que este aponta para o abismo da transcendência. Mas qual é a novidade disso? Que interesse é resguardado com a noção de metamorfose do mundo?

A metamorfose do mundo é o esboço de uma ontologia do presente. Em nossa tradição a filosofia nasce do espanto de que o mundo é. Que o mundo simplesmente exista, eis o que espanta. A admiração - como theoria - habitualmente foi compreendida como o distanciamento diante do mundo. $\mathrm{O}$ espanto, porém, foi erroneamente vinculado à harmonia entre o pensamento e o ser; segundo essa concepção, há como que um acordo reciproco, e é isso o que produz o espanto. A 
teoria visa, então, retendo a totalidade no logos, dar conta daquilo que espanta: A teoria e o espanto fazem um círculo: a vida contemplativa é o distanciamento originado nesse espanto. Confunde-se com ele. Mas, se já havia harmonia entre o ser e o pensar, ou entre o pensamento e o mundo, por que surgiu uma pergunta como "o que é o ser"? Ou melhor: qual a origem do gigantesco confronto sobre o ser? Essas perguntas nascem, porém, não da harmonia, mas do espanto, que se confunde com a indeterminação do mundo. Da indeterminação - e não do acordo - é que surge o espanto. A resposta a essas perguntas levou a curiosidade ou espanto original à noção de episteme, ou de teoria, ou seja, a curiosidade contrapondo-se ao caráter trágico do mundo grego já indicava uma tentativa de evasão e distanciamento frente aos conflitos de interesses; o interesse por teoria surge da mera curiosidade e depois acaba por afastar-se dela. No mundo rigoroso da episteme, o homem torna-se um espectador desinteressado e, à medida que vai se afastando do mundo, torna-se filósofo. O espanto, portanto, não se destaca e retroage diante de o mundo ser o que é. O espanto, ao contrário, se confunde com a indeterminação de algo como outro algo. O espanto é alteridade. Ele surge quando da revelação do aspecto e não da totalidade unívoca do mundo. O espanto indica uma zona de intransparência no mundo e está imerso na vida ativa. O espanto não é pathos, mas práxis, e, portanto, não deve ser entendido como um deixar-se levar por algo, o tolerar paciente, ou como contemplar extasiado o cenário do mundo; ao contrário, o êxtase é a vivência fugidia da revelação do aspecto à medida que, ao apontar para os limites do sentido, mantém o mundo aberto para o novo. 0 espanto não é um afastar-se que permanece envolvido pelo que é, mas faz parte da vivência do que não é. Aliás, o projeto de uma ciência (episteme) do ser enquanto ser nunca foi completada por Aristóteles devido a que, em sua radicalidade, nossa linguagem está fissurada do aspecto. Nesse sentido uma ciência do que está presente seria uma ciência da linguagem que já está sempre pressuposta na elaboração de qualquer ciência. Só poderia, então, ser uma ciência sempre procurada, mas definitivamente nunca encontrada, e isso não porque os conceitos irredutivelmente simples sejam atos puros, condição para que uma proposição seja verdadeira ou falsa, e que deles mesmos não se possa afirmar serem verdadeiros ou falsos e que, portanto, não se possa tematizá-los (Aristóteles, Met. IX, 1051b 25-28). Isso se deve, porém, não a que, como pensava Aristóteles, cada conceito corresponda a uma coisa, mas a que linguagem complexa em que estão esses conceitos seja a condição de que se possa falar de algo que seja ou não simples. Toda a tradição "onto-teo-lógica" da metafísica ocidental assentada na teoria buscou fundamentos para aquilo que é condição para qualquer discurso sobre fundamentos, e isso até a fenomenologia transcendental, onde a crise do homem é, na verdade, associada à crise de fundamentos das ciências, especialmente no caso da psicologia. Em sua prática normal, o psicólogo não encontra nenhum empecilho; porém, quando ele reflete sobre essa prática, sente-se totalmente perdido por falta de justificação de seus conceitos (Husserl, 1976, p. 365). Essa crux psicologiae, porém, a nosso ver, não se deve à falta de fundamentos, mas, ao contrário, precisamente à tentativa de encontrá-los. Essa tentativa de encontrar fundamentos à psicologia persiste na tradição da admiração ou teoria como dis- 
tanciamento. A crux psicologiae surge da crux vitae. Substituímos, assim, a noção tradicional do espanto como curiosidade ou admiração (thaumatzein), ou mesmo como estremecimento diante de algo, pela do espanto como basicamente inquietação, a que se confunde com a surpresa da revelação (aufleuchten) do aspecto. Esta revelação anda junto com a ambigüidade do significado das palavras na linguagem. O espanto, então, envolve o pensamento, mas não como se este fosse um super conceito teórico, ou como se fosse uma entidade misteriosa da alma. A inquietação não se deve a um distanciamento que envolve o todo do pensar pelo mundo ser assim e não de outro modo, mas simplesmente porque aí estão presentes apenas os ecos distantes do pensar, são os limites do que não é totalmente compreensivel, posto que não se pode dar conta plenamente das ambigüidades que, inesperadamente, surgem nos aspectos.

A linguagem ordinária - o solo áspero - forma um tapete. As "dobras" (plis) dessa aspereza são expressas nos aspectos. O aspecto é a ação levada a seu limite. O conceito de aspecto preserva sua própria característica de aparência externa de algo que está relacionado com o que permanece escondido, de semblante e, portanto, de fisionomia ou de ponto de vista. Isto é, os aspectos envolvem o próximo e o distinto; a relação, que subjaz a toda visão de mundo, entre algo e o que aponta para o outro. O caráter dispersivo da linguagem indicado no aspecto rompe com a noção de linearidade, ou seja, o aspecto é compreendido segundo o jogo de linguagem como, por exemplo, quando se trata do futuro, do passado ou do presente, e não de um tempo único. A noção mesma de aspecto rompe com a idéia de uma pura linha do tempo, pois aspecto é dispersão e antinomia. As categorias do aspecto, tais como, segundo Foucault, as chamam os "gramáticos", envolvem o acabamento e inacabamento, a continuidade, a interação, a iminência, a proximidade e o distanciamento, etc. O núcleo semântico do conceito de aspecto envolve as noções de species de espelhos e espécies de analogias, a difração do espectro, o desdobramento de espectros, o aspecto externo, que não é nem a coisa mesma nem seu contorno exato, o aspecto que se modifica com a distância, o aspecto que constantemente engana, mas que não desaparece, etc. (Foucault, 1997, v. 1, p. 282). Nesses exemplos aproxima-se a noção de aspecto com a de dobra (plis) e, portanto, da fragmentação e da diversidade da linguagem, mas a falta de uma concepção da linguagem ordinária distinta do modelo objetodesignação leva Foucault a tornar a arte romanesca ou poética como expressão dessa diversidade; por isso seu projeto de uma ontologia do tempo presente fica apenas sinalizada. Nossa proposta sai do fictivo para o ontológico. A gramática está embebida de facticidade. E isso é o que possibilita falar-se de "uma ontologia da dobra" ou de "uma ontologia do aspecto", o que possibilita a eliminação do monismo do ser. Por enquanto, é importante chamar a atenção para a radical indeterrminação dos conceitos, isto é, para a primazia da ambigüidade do aspecto em relação à comunidade dos juízos. Há algo de inacabado no aspecto que nem sempre está previsto na regra. A dobra, porém, entendida como uma volta sobre si, envolve sempre um desdobrar, uma vez que todo voltar-se sobre si, como as volutas do barroco, envolve um abrir-se para além do que já está dado. O desdo- 
brar é um manifestar, um abrir-se para. Este para além, expresso no desdobrar, é a abertura do aspecto. Não é o ser o primeiro transcendental, mas aquilo que torna possivel o sentido de qualquer coisa; a abertura na linguagem a partir da qual surge o sentido é o aspecto da significação. Aspecto é ultrapassagem (Über-weg). $\mathrm{O}$ aspecto é transcendental.

Os aspectos são negativamente relacionados com a vontade, uma vez que ninguém pode ser obrigado a ver aspectos, e são positivamente relacionados com a cultura no sentido em que, ver aspectos pressupõe toda uma formação. Pode-se ser educado a apanhar as sutilezas das palavras na linguagem poética, ou os detalhes de estilos pictóricos, musicais ou das várias formas de dança ou de moda, etc. Essa formação depende, portanto, do conceito fundamental de aspecto como aquilo que encanta ou provoca admiração, precisamente porque nos inquieta, pois não surge da mera contemplação da harmonia do mundo, mas, ao contrário, é da inquietação dos aspectos que advém a nossa necessidade de harmonia. Trata-se então de apanhar algo como algo, isto é, algo que envolve um outro algo e cuja expressão se mostra na ambigüidade do "como". A perda desse "como" equivale à desmundanização do mundo. Este seria o caso do cego para o aspecto, aquele que, como um sonâmbulo, anda pela casa sem despertar de seu sono. Ele não bate nos móveis, abre e fecha portas e janelas, sobe e desce escadas, ou sai para a rua; porém, ao deixar escapar o "como", perde os aspectos das coisas, os detalhes do que lhe está em torno. O que lhe está em torno não lhe provoca inquietação. A cegueira para o aspecto é uma degeneração da nossa gramática à medida que, perdendo-se a sutileza dos aspectos, seguir-se-iam regras cegamente, tal como fazem os computadores. Estaríamos então às voltas com a falácia da imediaticidade do sentido. Mas se a gramática é plana, então a descrição das palavras está inserida na vagueza e na indeterminação da linguagem, ou seja, na exceção à regra, no engano e, mais sutilmente, no aspecto, pois através dele abre-se o mundo como sentido em sua maior sutileza. Ainda que as regras de que tratamos não sejam entendidas de modo platônico, sem o conceito de aspecto, o ato de simplesmente seguir regras estaria fechado para o sentido. Por isso, embora não se trate de qualquer concepção que envolva essência ou substrato, a noção de apenas seguir regras lembra o tradicional algo enquanto algo, o que define a qüididade de algo, isto é, a noção do "enquanto algo" equivalente a outra coisa (aliud quid). O "enquanto" é agora definido pelo caráter dinâmico do "como". A noção de algo como algo passa a ser entendida não apenas enquanto modo de algo aparecer ou de ser empregado, mas o que leva ao limite do sentido, pois o que se procura destacar é caráter transitório do "como", de algo que remete a outro algo, um algo que não se distingue estaticamente de um outro e que a partir daí se caracterize como algo. O que se salienta é o "como", que constitui a oscilação dos aspectos e que origina o espanto de que algo remeta para um outro, e que ainda pareça continuar o mesmo. O aspecto, portanto, não é o outro que é apenas adjacente, mas a própria indeterminação do sentido em sua radicalidade. No aspecto esvai-se momentaneamente a certitudo do enquanto outro. 
Na conhecida figura pato-lebre, temos a imagem de um pato que é uma lebre, que é um pato. $\mathrm{O}$ espanto não se dá apenas pelo reconhecimento da diferença das figuras, mas pela oscilação das mesmas, pela instantaneidade desta passagem em que uma figura é vista como a outra. Nessa passagem, a vivência da significação é abertura para o outro, também aí não funciona a lógica da informação, e nem se pode explicá-la pelo discurso teórico. O que há de comum entre essas figuras se as tomarmos isoladamente? E também não se trata aqui de duplicar a linguagem, dizendo diante da figura: "Vejo-a agora como um pato", ou "Vejo-a agora como uma lebre"; com isso nada se acrescenta ao que vejo, pois não se trata aí de explicar a condição de toda a explicação. No caso do aspecto, porém, ocorre o espanto. A linguagem ordinária perde a sua aparente tranqüilidade, como quando, andando pelo campo, um vulto salta inesperadamente à nossa frente e gritamos: "Uma lebre!". Isso também se assemelha à vivência do aspecto. Nele, porém, há a ambigüidade de que, quando reconhecemos uma figura, ela já se transmuta noutra figura. Não há nenhuma informação que passe de uma figura para a outra, mas simplesmente a indefinição do espanto. Este "como" do aspecto também não é o mundo do ser-aí (Dasein) em sua diversidade de ocupações práticas e onde a linguagem é apenas mais uma dessas ocupações. O "como" é a sutileza da linguagem. Ora pato, ora lebre, eis o "como" vivenciado em sua fugacidade. Este apreender-se algo em sua fugacidade só é possivel porque aí se encontra a atmosfera rarefeita do pensamento. A passagem de uma figura à outra - pato-lebrepato - não se esgota em si mesma. A revelação do aspecto aponta para além dessa passagem. E essa radicalidade vivenciada no aspecto é o que ameaça arremeter para âmbitos vazios onde a linguagem desliza sem que nada the ofereça resistência: a ocultação metafísica. A radicalidade do aspecto, porém, sinaliza que apenas podemos alargar os jogos de linguagem de que participa o conceito de mundo, mas nunca habitar num outro mundo paralelo.

O que torna inalienável o conceito de aspecto é a ambigüidade, de onde surge a surpresa não como algo diante de algo, mas como um evento que envolve um eco distante do pensar, isto é, um evento cujo caráter de surpresa ocorre por não ser totalmente permeável ao pensamento. E isto porque o conceito de pensamento não é um super conceito nem uma força misteriosa e oculta da alma ou da consciência que possa ser transmitido pela linguagem. Lembremos que a noção de que a concepção da linguagem como meio que transporta a mensagem do pensar é tudo que se pretende rejeitar: o modelo objeto-designação. Pois a essência do pensamento encontra-se na gramática. O pensamento, então, tem seu significado nos diversos modos em que é usado. O conceito de pensar pode ser melhor compreendido na diversidade de jogos de linguagem de que participa, deixando, portanto, de ser algum enigma que pudesse ser eliminado por uma teoria filosófica ou científica. O caráter plurívoco do conceito de pensamento retira-o da aura de sublimidade ou imponderabilidade em que é normalmente compreendido e, desse modo, o "eco de pensamento" que ocorre na revelação do aspecto indica que aí há apenas um reconhecimento de algo que não pode ser totalmente explicado. O pensamento participa da surpresa quando da ambigüidade do aspecto, mas essa surpresa ocorre porque não pode ser totalmente apanha- 
da pelo pensamento. A perda do caráter cognotivista que geralmente acompanha o conceito de pensamento toma compreensível porque a espontaneidade do aspecto não pode ser apreendida desde o desvio de uma inferência.

No aspecto o pensamento é débil ou, noutras palavras, a regra como que perde sua força à medida que aponta para uma outra. Mas ainda que todo aspecto seja exceção à regra, nem toda exceção à regra é aspecto. Se a regra tem exceções que ajudam a compreendê-la, se é errando que se aprende a seguir regras, tal como os instrumentos que o ser-aí tem sempre à mão, e cujo defeito ou engano na aplicação revela a sua instrumentalidade, no caso dos aspectos estão em jogo as sutilezas da linguagem, que ao apontar para um outro, nos limites do sentido, provocam a admiração ou o espanto. E esse espanto vivenciado na revelação do aspecto é a origem do espírito de sutileza de que falava Pascal. De modo que não se trata de distinguir, mas, antes, de mostrar que a vida contemplativa surge da vida ativa para logo depois destacar-se dela como espanto. Se todo sentido é interno, e se o aspecto é a maior expressão de refinamento do "espírito", então é no aspecto que a relação conceitual interna se abre para a alteridade. $\mathrm{O}$ aspecto é alteridade, a mais próxima experiência do outro; por isso é que a falácia da imediaticidade do sentido, "seguir as regras cegamente", vale também para a temporalidade, ou seja, sem a vivência do aspecto não haveria a experiência da temporalidade. A revelação do aspecto não ocorre no tempo, mas a experiência do tempo só ocorre pela revelação do aspecto. O tempo edênico está fechado para nós e só surge como problema desde a fragmentação da temporalidade expressa na vivência da revelação do aspecto. Não se trata de simplesmente unir a temporalidade à práxis, mas de que, no "como", a práxis, ao situar-se no seu limite, abre o sentido da temporalidade - os jogos de linguagem onde aprendemos a usar os conceitos de presente, passado e futuro. Usamos distintamente o conceito de tempo; o tempo do iogue não é o tempo do financista, o tempo do camponês não é o do comerciante. Como não há um tempo único, o relógio apenas marca o que se expressa nos aspectos do mundo. Consultamos o relógio para saber se estamos atrasados, se já não é hora do almoço ou do entardecer, ou para não deixar derramar o leite, ou queimar a carne ou a torta no forno, etc. E se o tempo, portanto, não é algo, mas os usos dessa palavra, isso quer dizer que estão em jogo todas as palavras ou circunstâncias afins como a saudade, a esperança, as recordações, e assim por diante. Esses aspectos do tempo não são regidos pelo calendário. Como pode o relógio dar conta da minha saudade? Essas "inquietações" pelo que pode ou não ocorrer expressam os aspectos do tempo. O "como algo" é a fratura que possibilita a temporalidade: os usos do conceito de tempo. Os chimpanzés e os orangotangos usam instrumentos rudimentares, mas não têm tempo. A linguagem não se desdobra no tempo, mas a temporalidade é a práxis da linguagem. Sem linguagem não há tempo. Perder os aspectos do "como" equivale a fechar as possibilidades da compreensão da linguagem. E nosso objetivo é ampliar a compreensão de conceitos e não a sua explicação. As falhas do aspecto são expressão da finitude da compreensão. Não se trata, porém, de apenas associar o tempo com a atividade do ser-aí, e de colocar a compreensão do sentido no horizonte da temporalidade, nem muito menos de responder o que é o tempo, pois ele não é uma 
coisa. A gramática da nossa linguagem - enquanto flutuação (Schwanken) dos conceitos - mostra como o próprio tempo surge como sentido no aspecto. O "como" não é o modo de ser do instrumento, mas a expressão da subitaneidade do aspecto, esse limite a partir do qual surge o sentido do tempo. Os aspectos do tempo são os aspectos do mundo. Também há os aspectos do espaço, uma vez que a linguagem não é um super conceito, podendo-se falar em linguagem verbal, linguagem fisionômica, linguagem musical, linguagem pictórica, fotográfica ou linguagem arquitetônica, tanto quanto se pode falar do espaço cósmico, do espaço público ou privado, do espaço da sala de jantar, do espaço na poesia concreta, etc. O espaço e o tempo não são coisas, ou formas puras da sensibilidade, mas práxis que se mostram em jogos de linguagem distintos. Não há um espaço que seja algo no qual algo seja inserido ou concebido. Por isso, a gramática do espaço tem de dar conta de um campo conceitual afim, como distâncias, proximidades, profundidades, perspectivas, relações, movimentos, etc. Ou seja, a gramática do espaço - para além dos dêiticos aqui, ali, acolá, atrás, à frente de, etc. - está vinculada à noção de aspecto. Esse campo conceitual emerge no aspecto. Perspectiva é aspecto. Nessas atividades muitas vezes o conceito de distância pode ter melhor uso que o de espaço, já que esse uso emerge no aspecto e seu limite é a atividade que leva a um novo aspecto.

$\mathrm{O}$ aspecto, porém, é uma atividade que ocorre na planeza do mundo, isto é, o desoculto é constituído por essas atividades levadas ao limite. À conhecida figura pato-lebre podemos acrescentar outros exemplos, como a dos planos perpendiculares interseccionados por uma reta que atravessa as duas superfícies e parece ora destacar o aspecto côncavo, ora o convexo, ou a figura de um paralelepípedo cuja frente ora parece o fundo, ora vice-versa. A perda desses aspectos não expressa apenas um defeito fatal para a arquitetura, mas a cegueira para os aspectos do mundo, os diversos modos de funcionamento da linguagem e, portanto, a restrição na capacidade de convívio humano.

$\mathrm{Na}$ ambigüidade do aspecto, algo se mostra enquanto algo se oculta; enquanto uma figura aparece, a outra figura some, mas isso não quer dizer que uma figura se superponha à outra, desde planos distintos, como se o jogo entre o que se oculta e o que se desoculta já não estivesse sempre à mostra. Não há hierarquias no mundo. A passagem de uma figura à outra - no aspecto - é uma atividade que está sempre à mostra; no entanto, essa atividade parece "imponderável" à medida que, arremetendo-se para além, tende a se tornar presa de âmbitos ocultos. Mas o oculto não interessa, isto é, é desde o que interessa - a inalienabilidade do aspecto - que surge o fascínio pelo que está oculto. O oculto em si mesmo não tem nenhuma força, pois não somos primeiramente atraídos pelo oculto; é desde o que está desoculto que podemos buscar refúgio no oculto. O oculto é a ilusão metafísica. O metafísico é o operar no vazio, e aí não há nenhum interesse. 0 oculto é o esvaziamento da práxis. O oculto é o andar sem resistência. Mas, então, de onde surge o oculto? O oculto surge do desoculto. O que está sempre à mostra é a condição humana. A condição humana se expressa na complexidade e na vagueza da linguagem ordinária. A tradição "onto-teo-lógica" é a tentativa de unificar a complexidade da linguagem em super conceitos - substância, mente, 
consciência, eu, sujeito, etc. Tenta-se, assim, aprisionar o que está à mostra no fluxo da vida em algum esquema conceitual ou numa forma do mundo, e com isso procuram-se no oculto razões para o désoculto. Mas como pode o oculto justificar o desoculto?

Contra a tradição que vê o espanto como um distanciamento contemplativo da harmonia do mundo e que se deixa convocar por ela, a revelação do aspecto está vinculada a uma indeterminação que, em sua radicalidade, resulta na abertura de sentido. Se o significado de uma palavra se dá no fluxo da vida, o aspecto é a atividade que, não como admiração externa, mas como revelação (Aufleuchten), indica em sua radicalidade a indeterminação da própria vida. A necessidade de harmonia surge do conflito das visões de mundo como tentativa de fundamentar o que não tem fundamento último. Por isso é que a ataraxia é a única opção para quem o não-convencimento de qualquer posição teórica ameaça jogar no drama da condição humana expresso na linguagem. O cético confunde ataraxia com autenticidade. Desse modo, a teoria do filósofo dogmático e a ataraxia do cético são modos de ocultação. O dogmático oculta a complexidade do interior sob super conceitos, enquanto que a ataraxia almejada pelo cético não pode ser assemelhada à condição humana, pois é apenas uma parte dela que, aliás, se pode obter ou perder a qualquer momento. O teórico e o cético acabam por ocultar a vagueza dos conceitos psicológicos, buscando dar razões para o que não pode ser explicado, ou optando por uma vida "normal" - o mundo dos sonâmbulos. O cético acha-se sábio refugiando-se num mundo onde nada de relevante acontece. Não haveria nada demais em suspender o juízo diante das insolúveis disputas filosóficas, se isso não envolvesse, por parte do cético, a ocultação daquilo que leva às disputas filosóficas e à sua posterior opção pela suspensão dessas mesmas disputas. A harmonia do teórico e a ataraxia do cético são as duas faces opostas de uma mesma moeda: a ocultação da vagueza e da indeterminação da linguagem. Opondo-se ao teórico e ao cético, coloca-se a noção metamorfose do mundo como o debater-se contra os limites do sentido. A vivência da significação - no aspecto - mostra que mundo é sempre aventura. Mundus opus incertum est.

A pluralidade de sentidos, ou de aspectos que podem ter as palavras, faz com que os diversos âmbitos da linguagem se mostrem como fisionomias. O significado de uma palavra, o querer dizer, ou o ter em mente - meinen - é como alguém que se aproxima (PU\#457). Compreender a significação de uma palavra é como apreender os detalhes de um rosto que parece assim e assim. A noção de linguagem como fisionomia resultou das imagens inconstantes e imprecisas da face humana. É o caráter vago e impreciso da linguagem - expresso no "como" - que extrapola a linguagem binária dos computadores e que rompe com o "deve" (muss) da lógica formal. A permeabilidade dos jogos de linguagem pode ser melhor compreendida com as noções de vivência da significação ou de atmosfera de uma palavra, como no caso exemplar da expressão "sentimento-se". O "se" não está por um sentimento, pois o sentimento revela apenas a atmosfera dessa palavra, um certo aspecto dela, um modo de entonação ao se pronunciá-la. Enfim, a palavra "se" não é algo que indica a "inautenticidade" do linguajar cotidiano, mas, ao contrário, as autênticas possibilidades de funcionamento da linguagem. 
O interesse do conceito de aspecto contrapõe-se, então, ao modelo cognitivo que reduz o âmbito dos conceitos psicológicos ao de natureza humana, que pode ser explicada pela biologia, antropologịa ou neurologia. Esse modelo se expande à medida que essas ciências perdem seu verdadeiro fundo: a forma de vida que the deu origem. Esta expansão tem como conseqüência a ocultação do que já está sempre presente na linguagem. Se, porém, a ciência surpreende é por que está aí em jogo a forma de vida que a originou, e esta só pode ser expressa numa linguagem que extrapola a metodologia das ciências. Pode-se explicar um rosto triste, ou alegre, ou cínico, desde a contração dos nervos ou dos músculos da face e suas ligações com o cérebro, mas isso porque já dominamos os conceitos de tristeza, alegria ou cinismo. Dominar esses conceitos é o modo originário de vermos as coisas, pois se os conceitos se impõem no fluxo da vida, é porque expressam nossos interesses. O que nos preocupa então é a possibilidade de dissolução de certos interesses, o que poderia alterar radicalmente nosso modo de compreender - a nossa forma de vida, isto é, que o conceito de natureza humana possa vir a preencher todo âmbito dos conceitos psicológicos. Não se trata, portanto, simplesmente distinguir o "como" do "quê", mas de reconhecer sua relação dramática. O drama da metafísica - oculto/desoculto - é o que distingue a condição humana da natureza humana. No eco longínquo do pensamento, na revelação do aspecto, a harmonia da linguagem e da realidade abre-se para novas alternativas, por isso o aspecto é como um vértice em que se podem apanhar certos âmbitos da linguagem em perspectiva. A debilidade do pensamento no aspecto revela a contingência da linguagem e da realidade, e que a complexidade dos conceitos psicológicos não pode ser apresentada sob a rigidez e a clareza de super conceitos, como foi concebido na tradição filosófica. O pensamento, a linguagem e o mundo, considerados não mais como super conceitos, deixam exposta a contingência da linguagem ordinária, e com isso mostram que as ciências, enquanto partícipes da aventura do mundo, não têm a última palavra. Se o conhecimento científico viesse a ser algum dia o único possível, não haveria aí ninguém que conhecêssemos. O que preocupa, portanto, não é que a ciência surpreenda, mas a possibilidade de que algum dia a ciência deixe de surpreender.

$\mathrm{O}$ aspecto é a subitaneidade da metamorfose. A indeterminação radical da linguagem. A fulguração do aspecto é a falha ontológica que permite a emergência do sentido. Elimina-se, com o conceito de revelação do aspecto, a dureza das ontologias tradicionais e, ao compreender-se a vagueza e a indeterminação radicais da linguagem e da realidade, somos levados a reconhecer a indigência ontológica do mundo. A ambigüidade da revelação dos aspectos aponta para o abismo da transcendência, quando a linguagem ameaça andar no vazio. O fascínio pelo oculto ocorre quando começamos a perder a prudência gramatical e investimos contra os limites do que já temos acesso. A noção de metamorfose do mundo parece grandiloqüente, mas com ela apenas quisemos destacar que o fenômeno do mundo interior não se ocultou, pois, com a noção de algo como algo, a gramática se torna a descrição incompleta da significação. O significado do interior dáse no fluxo da vida (Fluss des Lebens) (LWPP, 2, p. 38). O significado do interior, 
como aquilo que sempre se pressupõe quando tratamos com seres humanos, mostra-se na linguagem, e esta, à medida que extrapola a mera lógica da informação, abre-se no aspecto. A emergência do sentido - no aspecto - se dá como alteração de sentido e tende a ser sempre ampliação de sentido.

Apenas uma concepção da linguagem que pressuponha a flutuação dos conceitos pode dar conta da vagueza gramatical do interior. $\mathrm{E}$, não havendo confinamento da gramática, ela se confunde com a finitude da compreensão da linguagem a que já temos sempre acesso. A finitude da compreensão não envolve algo que, com nossa morte, indique o fim da própria linguagem, pois a morte é um evento público e só aprendemos algo sobre nossa morte pela experiência da dos outros. O medo da morte produz uma forte necessidade de convenção que, por vezes, oculta os aspectos da morte. A finitude da compreensão não é indicada pela morte, mas pela dificuldade de encontrar transparência gramatical, de apanhar todas as possibilidades abertas nos aspectos. A morte tende a arremeter-se para fora da linguagem, mas a gramática, imersa na facticidade, é sempre expressão de nossos interesses. E nosso interesse maior se encontra na metamorfose do mundo, à medida que nela se expressa o espírito de sutileza (Witz). A metamorfose do mundo não é uma mera vagabundagem do desejo. Mudar aquilo a que temos acesso - a nossa forma de vida - é duro. A dificuldade de nosso esforço encontra-se na resistência às alternativas para o que já dominamos. O que dominamos nos coage. A metamorfose do mundo é o alargamento desses limites. E isso só ocorre porque o mundo está fundamentalmente aberto no aspecto; pois se no aspecto o pensamento aponta para outras direções, é porque também ele aí pode perder-se. Porém, onde o pensamento vacila - na ambigüidade do aspecto - reside a força da imaginação. Ela é parte do mundo da consciência ou da vagueza do conceito de interior. Lembremos que o próprio conceito de conceito é vago. A distinção entre o interior e o exterior é gramatical. Ela faz parte do modo como sempre usamos essas palavras, pois não podemos imaginar ou pensar algo interior sem o exterior que lhe corresponde, e ai está a origem das ilusões filosóficas, como se o mundo interior fosse um espelho do mundo exterior, como se se pudesse inclinar para o exterior para dar conta do interior, ou se se pudesse inclinar para o interior a fim de, pensando desde si mesmo, dar conta do que é exterior, isto é, como se a realidade do interior fosse imposta desde o exterior, ou, ao contrário, como se a realidade do exterior fosse obtida desde o interior. A dificuldade sempre foi a de passar pelo fosso que distinguia o interior e o exterior. Porém, uma vez que esses conceitos passam a ser compreendidos pelo seu uso na linguagem, então podemos falar deles como se fala normalmente de cadeiras, mesas, frio, calor, luzes e sombras, medo, angústia ou esperança, desde que se leve em conta a distinção gramatical entre exterior e interior. Mesas e cadeiras não têm interior. O mundo interior não é o mundo das coisas, por isso nos relacionamos com os seres humanos de modo diferente ao dos objetos. A condição humana pressupöe 0 interior, enquanto os objetos pressupõem o exterior. O cérebro não tem interior, só o homem o tem. Certos animais têm cérebro, mas não têm interior. Cérebros não pensam, não ficam tristes e nem esperam. As proposições sobre eventos cerebrais 
se distinguem das proposições sobre a consciência, pois dizer que alguém tem uma lesão cerebral não é o mesmo que dizer que tem a consciência ferida; distúrbios cerebrais não são da mesma natureza dos problemas de consciência. É preciso tomar o cuidado de, ao distinguir cadeiras e mesas dos seres humanos que têm interior, não retornar ao que se pretende abandonar: a distinção entre processos interiores e exteriores e a noção também aí originada de "conteúdo da consciência". O significado de consciência é dado pelos seus usos na linguagem. A consciência não é um processo interposto entre a linguagem e o mundo. A consciência do mundo - como algo que se distancia dele para julgá-lo - é "infeliz", mas, no mundo interior, a infelicidade é apenas um de seus variados modos de expressão. De outro lado, como a gramática é plana, o conceito de interior não é o "suprasensível", ou o "mundo invertido" onde estariam as condições de possibilidade de tratar dos eventos externos, ou das re-presentações tomadas como cópias da sensibilidade. $\mathrm{O}$ mundo interior é o âmbito das sensações, emoções, sentimentos, pensamentos, disposições e as formas de convicção como crenças, certezas, dúvidas, etc. $\mathrm{O}$ interior tem muitas dobras, pois a linguagem é polifônica.

\section{Referências bibliográficas}

ARISTÓTELES. Metaphysica. Oxford Classical Texts, Biblioteca Oxoniensis, 1988.

FOUCAULT, M. Distance, aspect, origine. In: — . Dits et écrits-1954-1988. Paris: Gallimard, 1996. v. 1, p. $272-285$.

HEIDEGGER, M. Sein und Zeit. Tübingen: Max Niemeyr Verlag, 1986.

HUSSERL, E. La crisis des sciences europeènes et la phénoménologie transcendentale. Paris: Gallimard, 1976.

PASCAL, B. Pensamentos. Porto Alegre: Globo, 1973.

NIETZSCHE, F Fragmentos póstumos. Trad. O. Giacóia Junior. Campinas: Universidade Estadual de Campinas, 1996.

— A origem da tragédia. Lisboa: Guimarães, 1972.

WITTGENSTEIN, L. Philosophishe Untersuchungen (PU). Frankfurt am Main: Suhrkamp, 1984. . Investigações filosóficas (IF). São Paulo: Abril Cultural, 1984.

- Remarks on the philosophy of psychology (RPP, 1). Oxford: B. Blackwell, 1980. v. 1.

- Remarks on the philosophy of psychology (RPP, 2). Oxford: B. Blackwell, 1980. v. 2.

- Last writings on the philosophy of psychology - preliminary studies of part II of philosophical investigations (LWPP, 1). Oxford: B. Blackwell, 1982. v. 1.

B. Blackwell, 1992 . v. 2. 